\title{
An Intelligent Prediction Method of the Karst Curtain Grouting Volume Based on Support Vector Machine
}

\author{
Jiandong Niu $\left(D,{ }^{1}\right.$ Bin Wang, ${ }^{1}$ Haifa Wang, ${ }^{1}$ Zhiwei Deng, ${ }^{2}$ Jianxin Liu, ${ }^{3}$ Zewei Li, ${ }^{1}$ \\ Guanjun Chen, ${ }^{4}$ and Botao Zhang ${ }^{5}$ \\ ${ }^{1}$ School of Civil Engineering, Central South University, Changsha 410075, China \\ ${ }^{2}$ School of Computer Science and Engineering, Central South University, Changsha 410000, China \\ ${ }^{3}$ Swan College, Central South University of Forestry and Technology, Changsha 410000, China \\ ${ }^{4}$ Hunan Hongyu Engineering Group Co., Ltd., Changsha 410000, China \\ ${ }^{5}$ Changsha Hengde Geotechnical Engineering Technology Co., Ltd., Changsha 410000, China \\ Correspondence should be addressed to Jiandong Niu; niudong@csu.edu.cn
}

Received 4 September 2020; Revised 10 October 2020; Accepted 12 October 2020; Published 7 November 2020

Academic Editor: Yanlin Zhao

Copyright (C) 2020 Jiandong Niu et al. This is an open access article distributed under the Creative Commons Attribution License, which permits unrestricted use, distribution, and reproduction in any medium, provided the original work is properly cited.

\begin{abstract}
The prediction of the grouting volume is a very important task in the grouting quality control. Because of the concealment and complexity of the karst curtain grouting engineering, there is little research on the prediction of the karst curtain grouting volume (KCGV), and the prediction is hindered by the practical problems of small samples, high dimensions, and nonlinearity. In the study, based on the basic idea of support vector machine (SVM), a multiparameter comprehensive intelligent prediction method of the KCGV is proposed, which overcomes the limitation of few sample data in practical engineering. This method takes the grouting construction conditions and the slurry conditions which control the slurry diffusion as the input parameters, which are the basic data which can be easily obtained in the field grouting process. This feature greatly improves the prediction accuracy and generalization performance of the method. The intelligent prediction method of the KCGV based on SVM is applied to a typical karst curtain grouting project. The mean absolute error of the prediction results is $3.47 \mathrm{~L} / \mathrm{m}$, and the mean absolute percentage error of the prediction results is $5.97 \%$. The results show that the proposed prediction method has an excellent prediction effect on the KCGV and can provide practical and beneficial help for the field karst curtain grouting project.
\end{abstract}

\section{Introduction}

Karst landforms are widely distributed in southwest China $[1,2]$. In these karst developed areas, the antiseepage of karst strata is a common challenge [3-8]. In the current theoretical analysis, numerical simulation, and experimental study of rock cracks [9-31], there is little research on karst cracks and their leakage. The grouting method has been more and more widely used as an effective means to control water leakage disasters [32-36]. Karst curtain grouting is a reliable method to solve the problem of karst leakage according to the special conditions of the karst area [37]. The karst curtain grouting volume (KCGV) is an important parameter in the design and construction of karst curtain grouting engineering, which directly affects the quality and antiseepage effect of karst curtain grouting [38]. Therefore, the scientific and accurate prediction of the KCGV will provide more quality control information for karst curtain grouting engineering.

The traditional methods for predicting grouting volume can be divided into two categories. One is the artificial empirical prediction method, which is basically based on the engineering experience of technicians and depends on the artificial experience to predict the grouting volume. Sohrabi-Bidar et al. [39] established an empirical estimation method of grouting volume by taking the Bakhtiari dam site as a case study. Gustafson and Stille [40] established a prediction method of grouting volume in grouting construction based on empirical knowledge according to grouting characteristics and hydrogeological data. However, due to the roughness and difference of empirical estimation, the results 
will have a great impact on the quality and cost of the project. The other is the traditional statistical prediction method, which mainly uses regression cluster analysis to establish a prediction model on the basis of collecting a large number of grouting data. Sadeghiyeh et al. [41] established a statistical prediction model of grouting volume on the basis of statistics on the permeability and groutability of rock mass at the Ostur dam site. Song and Liu [42] obtained the prediction model of grouting volume in the karst area based on the statistics of curtain grouting data of the Zhongguan iron mine in recent three years. However, the application effect of this kind of method is not very ideal, and there is no good application promotion.

With the emergence of an intelligent algorithm, the intelligent grouting prediction method has been applied to the prediction of grouting volume. In this method, artificial intelligence is applied to the grouting engineering of rock mass, and the intelligent prediction model of grouting volume is established based on all kinds of intelligent algorithms to realize the prediction of grouting volume. According to the commonly used intelligent algorithms, this kind of method includes the fuzzy theory prediction method, the grey theory prediction method, and the neural network prediction method. Chen and Tao [43] established a fuzzy comprehensive evaluation model for the optimization of a grouting scheme to predict grouting volume. Cheng and Hoang [44] established an evolutionary fuzzy $k$-nearest neighbor inference model to predict grouting volume. Markou et al. [45, 46] used the fuzzy linear regression method to estimate grouting volume. However, because the membership degree and the weight of the index of the fuzzy theory prediction method are not easy to be determined, and the evaluation results obtained by different evaluation models are different, the fuzzy theory prediction method has many shortcomings and does not have good practicability in engineering practice. $\mathrm{Li}$ and Shen [47] used the grey theory prediction model to predict grouting volume. However, the grey theory prediction method is mainly based on a large number of grouting data and does not consider the grouting mechanism, so its science and feasibility need to be verified. Wang and Hao [48] proposed and established a genetic neural network model for solving grouting volume, and the genetic neural network method was used to predict grouting volume. Hao et al. [49] introduced the backpropagation neural network and the information diffusion method into grouting practice to predict grouting volume. Tekin and Akbas $[50,51]$ constructed the artificial neural network model and the adaptive neurofuzzy inference system model to predict grouting volume. Liao et al. [52] developed the radial basis function neural network to predict the grouting volume of infiltration grouting. However, the neural network prediction method lacks a unified mathematical basis, and its structure selection and initial value setting of weights need the help of experience, and the model obtained is usually a local optimal solution rather than a global optimal solution, so its generalization performance is poor. In addition, this method is a learning method based on large samples, and only enough learning samples can train a prediction model with high accuracy. The actual situation is that there cannot be enough learning samples in the process of the grouting test and construction, and there are only small sample data in most cases. Therefore, the reliability of the neural network prediction method is poor.

To sum up, there are many irrationalities in the existing prediction methods of grouting volume in grouting engineering, and there is little research on the prediction of the KCGV. In addition, due to the concealment and complexity of the karst curtain grouting project, the sample data in the actual project is very limited. Moreover, most of the factors affecting the KCGV are random and uncertain, and many of them often influence each other, resulting in great discreteness of grouting data. As a result, there is a complex nonlinear relationship between the KCGV and its influencing factors. It shows that the prediction of the KCGV is faced with the problems of small samples, high dimensions, and nonlinearity. Therefore, it is necessary to put forward a new and more reliable method to predict the KCGV.

In machine learning methods, the support vector machine (SVM) is a very effective tool to solve learning and prediction problems in complex situations [53]. Verbiest et al. [54] pointed out that the SVM algorithm is one of the most powerful, popular, and accurate classifiers. At present, SVM has been widely used in civil engineering to solve the problems of classification and regression prediction [5558]. The SVM model even has excellent performance in solving practical problems such as small samples, high dimensions, and nonlinearity $[59,60]$. Therefore, SVM can be used to predict the KCGV.

In this paper, SVM is introduced into the prediction of the KCGV, and the main factors affecting the KCGV are selected as prediction factors. Based on these, an intelligent prediction method of the KCGV based on SVM is proposed. The method comprehensively considers the influence factors such as grouting construction conditions and slurry conditions and overcomes the obstacles of limited sample data, high dimensions, and nonlinearity in practical engineering, which greatly improves the prediction accuracy. The rationality and applicability of the proposed method are verified by a typical karst curtain grouting project.

\section{Methodology}

2.1. SVM. SVM is a general machine learning method based on the statistical learning theory, which has a good generalization performance for the statistical learning problems with small samples. The learning method of SVM is established according to the structural risk minimization criterion, and its algorithm is a convex quadratic optimization problem, which ensures that the obtained solution is the global optimal solution. The basic idea of SVM is to map the input space to a high-dimensional feature space based on the nonlinear transformation defined by the kernel function and to find a nonlinear relationship between input variables and output variables in this high-dimensional space. The basic structure of SVM is shown in Figure 1.

For the regression problem of SVM, the problem of fitting the data $\left(x_{i}, y_{i}\right)\left(i=1,2, \cdots, n, x_{i} \in R^{n}, y_{i} \in R\right)$ with the linear fitting function $f(x)=\omega x+b$ should be considered 


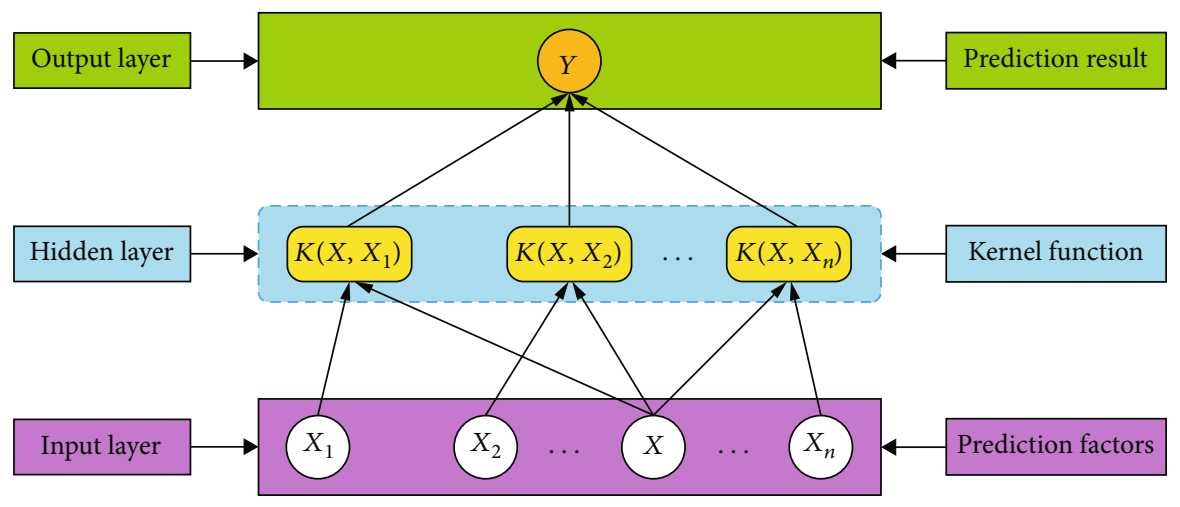

FIGURE 1: The basic structure of SVM.

first. Suppose that all training data are fitted with a linear function without error under $\varepsilon$ precision, that is,

$$
\left\{\begin{array}{l}
y_{i}-\omega x_{i}-b \leq \varepsilon \\
\omega x_{i}+b-y_{i} \leq \varepsilon
\end{array}(i=1,2, \cdots, n),\right.
$$

where $\omega$ is the weight vector, $b$ is the threshold, $x_{i}$ is the input vector of the $i$ th sample, $y_{i}$ is the target value of the $i$ th sample, and $n$ is the sample size.

The optimization goal is to minimize $1 / 2\|\omega\|^{2}$. According to the statistical learning theory, a better generalization ability can be achieved under this optimization goal. Considering the fitting error, the relaxation factors $\xi_{i} \geq 0$ and $\xi_{i}^{*} \geq 0$ are introduced. Equation (1) can be changed as follows:

$$
\left\{\begin{array}{l}
y_{i}-\omega x_{i}-b \leq \varepsilon+\xi_{i} \\
\omega x_{i}+b-y_{i} \leq \varepsilon+\xi_{i}^{*}
\end{array}(i=1,2, \cdots, n) .\right.
$$

The actual risk considered by the SVM structure is a combination of empirical risk and confidence range. It is necessary to control the complexity of the function to reduce the confidence range, which is to make the regression function the flattest. Therefore, the optimization goal is to minimize Equation (3) given as follows:

$$
\Phi\left(\omega, b, \xi_{i}, \xi_{i}^{*}\right)=\frac{1}{2}\|\omega\|^{2}+C \sum_{i=1}^{n}\left(\xi_{i}+\xi_{i}^{*}\right)
$$

where $C(C>0)$ is the penalty parameter, which indicates the degree of punishment for samples that exceed error $\varepsilon$.

The above optimization problem is transformed into its dual problem by introducing Lagrange multiplier $\alpha_{i}, \alpha_{i}^{*}(i=$ $1,2, \cdots, n)$. The solution goal is to maximize Equation (4) given as follows:

$$
\begin{aligned}
W\left(\alpha, \alpha^{*}\right)= & -\frac{1}{2} \sum_{i, j=1}^{n}\left(\alpha_{i}-\alpha_{i}^{*}\right)\left(\alpha_{j}-\alpha_{j}^{*}\right)\left(x_{i} x_{j}\right) \\
& +\sum_{i=1}^{n} y_{i}\left(\alpha_{i}-\alpha_{i}^{*}\right)-\varepsilon \sum_{i=1}^{n}\left(\alpha_{i}+\alpha_{i}^{*}\right) .
\end{aligned}
$$

The constraint is Equation (5) given as follows:

$$
\sum_{i=1}^{n}\left(\alpha_{i}-\alpha_{i}^{*}\right)=0\left(0 \leq \alpha_{i}, \alpha_{i}^{*} \leq C, i=1,2, \cdots, n\right) .
$$

Based on the maximization function above, the regression function of SVM is as follows:

$$
f(x)=\omega x+b=\sum_{i=1}^{n}\left(\alpha_{i}-\alpha_{i}^{*}\right)\left(x x_{i}\right)+b .
$$

For a nonlinear problem, the original problem can be mapped into a linear problem in the high-dimensional feature space by the nonlinear transformation, and then, it can be solved. In the high-dimensional feature space, the inner product operation in linear problems can be replaced by kernel functions, that is,

$$
K\left(x_{i}, x_{j}\right)=\Phi\left(x_{i}\right) \cdot \Phi\left(x_{j}\right)
$$

Kernel functions can be realized by functions in the original space, so it is not necessary to know the specific form of nonlinear transformation. In this way, the nonlinear function regression problem can be transformed into maximizing Equation (8) given below under the constraint equation (5):

$$
\begin{aligned}
W\left(\alpha, \alpha^{*}\right)= & -\frac{1}{2} \sum_{i, j=1}^{n}\left(\alpha_{i}-\alpha_{i}^{*}\right)\left(\alpha_{j}-\alpha_{j}^{*}\right) K\left(x_{i}, x_{j}\right) \\
& +\sum_{i=1}^{n} y_{i}\left(\alpha_{i}-\alpha_{i}^{*}\right)-\varepsilon \sum_{i=1}^{n}\left(\alpha_{i}+\alpha_{i}^{*}\right) .
\end{aligned}
$$

The obtained regression function of SVM is as follows:

$$
f(x)=\sum_{i=1}^{n}\left(\alpha_{i}-\alpha_{i}^{*}\right) K\left(x, x_{i}\right)+b .
$$

The commonly used kernel functions mainly include

(1) the polynomial kernel function given as follows: 


$$
K(x, y)=(x y+1)^{d}(d=1,2, \cdots, n)
$$

(2) the radial basis function kernel given as follows:

$$
K(x, y)=\exp \left(-\frac{\|x-y\|^{2}}{\sigma^{2}}\right)
$$

(3) the Sigmoid kernel function given as follows:

$$
K(x, y)=\operatorname{th}[\Phi(x y)+\theta]
$$

In the high-dimensional nonlinear spaces, the radial basis function kernel can usually obtain satisfactory results [61, $62]$.

2.2. The Prediction Method of the KCGV Based on SVM. After the karst curtain grouting is completed, the volume of slurry injected per unit length of grouting hole is called the karst curtain grouting volume (KCGV). It reflects the difficulty level of grouting and whether the rock mass can be grouted. The KCGV is affected by many factors. In this paper, the representative parameters are selected as prediction factors from many influencing factors. These main influencing factors include the grouting time $(T)$, the length of grouting section $(L)$, the grouting pressure $(P)$, the grouting flow rate $(Q)$, and the water:cement ratio of slurry $(W: C)$. These main influencing factors can basically reflect the two control conditions of slurry diffusion, namely, grouting construction conditions and slurry conditions.

Because the relationship between the KCGV and its main influencing factors is often not a simple linear relationship, it is difficult to use a linear mathematical equation to express the relationship between them. The study combines the basic idea of SVM with the main factors affecting the KCGV and uses SVM to express the mapping relationship between the KCGV and its main influencing factors; that is, the nonlinear relationship between the KCGV and its main influencing factors can be expressed by the SVM function $S\left(x_{1}, x_{2}, \cdots, x_{n}\right)$ given as follows:

$$
\left\{\begin{array}{l}
Y=S(X), \\
S(X): R^{n} \rightarrow R
\end{array}\right.
$$

where $X=\left(x_{1}, x_{2}, \cdots, x_{n}\right)$ are the main factors affecting the $\mathrm{KCGV}$, that is, the grouting time $(T)$, the length of grouting section $(L)$, the grouting pressure $(P)$, the grouting flow rate $(Q)$, the water: cement ratio of slurry $(W: C)$, and $Y$ is the KCGV.

In order to establish the nonlinear mapping relationship between the KCGV and its main influencing factors $X=\left(x_{1}\right.$ $\left., x_{2}, \cdots, x_{n}\right)$, the existing grouting sample data are used for learning. According to the SVM theory, the nonlinear approximation function between the KCGV and its main influencing factors is as follows:

$$
S(X)=\sum_{i=1}^{n}\left(\alpha_{i}-\alpha_{i}^{*}\right) K\left(x, x_{i}\right)+b,
$$

where $S(X)$ represents the grouting volume corresponding to the main influencing factors of the KCGV, $n$ is the number of learning samples, $K\left(x, x_{i}\right)$ is the kernel function, and $\alpha_{i}, \alpha_{i}^{*}$ are the Lagrange multipliers of SVM, $0 \leq \alpha_{i}, \alpha_{i}^{*} \leq C, C$ is the penalty parameter.

In this study, the proposed prediction method of the KCGV based on SVM is shown in Figure 2, which mainly includes three parts: the acquisition of input parameters, the establishment of the intelligent prediction model based on SVM, and the output of model application.

Step 1. determines two types of input parameters that affect the KCGV. These parameters are based on the data of the grouting process and the slurry properties obtained from the field grouting. The grouting construction condition parameters can be obtained from the grouting process data, including the grouting time $(T)$, the length of grouting section $(L)$, the grouting pressure $(P)$, the initial grouting flow rate $\left(Q_{i}\right)$, and the end grouting flow rate $\left(Q_{e}\right)$. The slurry condition parameters can be obtained from the slurry property data, including the initial water:cement ratio of slurry $\left(W: C_{\mathrm{i}}\right)$ and the end water : cement ratio of slurry $\left(W: C_{\mathrm{e}}\right.$ ). The input parameters in this study are the basic data that can be easily obtained in the process of field grouting and do not need too much exploration testing and calculation. Therefore, the prediction method has good generalization performance.

Step 2. establishes an intelligent prediction model based on SVM. The procedures are (1) to input the selected grouting data set as learning samples; (2) to select SVM model parameters according to learning samples, including kernel function selection and penalty parameter selection; and (3) to study and train according to needs and establish an SVM prediction model.

Step 3. applies the established intelligent prediction model to the actual projects. The KCGV can be predicted. By comparing and analyzing the predicted value and the actual value, the rationality and applicability of the model can be verified.

\section{Verification}

3.1. The Typical Karst Curtain Grouting Project. The typical case of karst curtain grouting project is the antiseepage curtain grouting project of the Panlong lead-zinc mine, a protective project in the reservoir area of the Datengxia water control project in Guangxi, China. The Datengxia water control project is a large-scale water conservancy project with comprehensive utilization of flood control, shipping, power generation, and irrigation. The normal water level of the reservoir is $61.0 \mathrm{~m}$. After the water storage of the Datengxia 


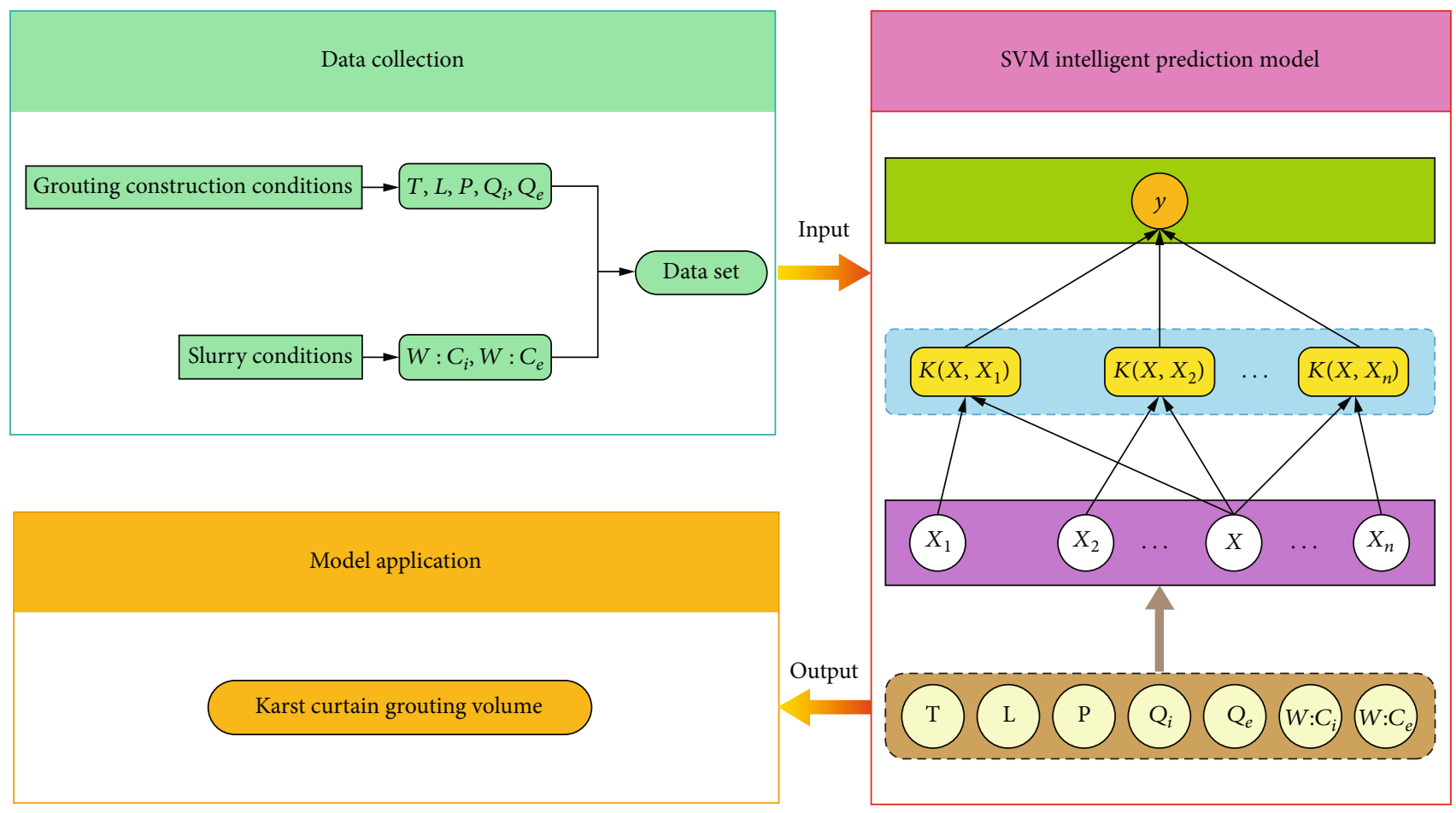

FIgURE 2: The prediction method of the KCGV based on SVM.

water control project, the return water level of Qianjiang river on the east side of the Panlong lead-zinc mine will reach $61.5 \mathrm{~m}$, and the reservoir leakage will affect the production safety of the Da-Ling section of the Panlong lead-zinc mine. Therefore, an antiseepage curtain is arranged on the east side of the mining area of the Da-Ling section to prevent the influence of the river uplift of Qianjiang river on mine production. The plane position of the axis of the antiseepage curtain is shown in Figure 3.

According to the geological data of the field geological survey, the Shanglun formation aquifer of the lower Devonian is the direct water-filled aquifer of the Da-Ling section of the Panlong lead-zinc mine, which is the curtain protection section of the antiseepage curtain project. The condition of the strata revealed by the grouting holes and the observation holes on both sides of the curtain shows that the karst in the construction site of the curtain grouting project is mainly developed in dolomite. The statistical results of karst revealed by drilling are shown in Figure 4.

The water-pressure test before grouting is carried out in the grouting holes in the karst area of Shanglun formation on the curtain line. The statistical results of the subsection and subelevation of the water-pressure test of the Shanglun formation on the curtain line are shown in Figure 5.

As shown in the above figures, the degree of karst development and the water permeability of rock strata decrease gradually with the increase of the depth of strata. By comparing and analyzing the degree of karst development and the results of the water-pressure test, it can be concluded that, in the dolomite stratum of Shanglun formation, the section above the elevation of $-80 \mathrm{~m}$ is the section of the fracturekarst cave water with strong permeability, the section of the elevation of -80 to $-120 \mathrm{~m}$ is the section of the karst cavefissure water with medium permeability, and the section below the elevation of $-120 \mathrm{~m}$ is the section of the karst fissure water with weak permeability.

3.2. Method Verification. The purpose of the part is to verify the rationality and applicability of the proposed prediction method of the KCGV by the field test of the typical karst curtain grouting project. In the karst curtain grouting test, a typical section which can generally represent the characteristics of karst development in the grouting area is selected as the field grouting test section. The karst curtain grouting test sections include two sections with different characteristics of karst development. Among them, the northern grouting test section represents the area of strong karst development, while the southern grouting test section represents the area of weak karst development. The plane layout and profile of the northern and southern grouting test sections are shown in Figures 6 and 7.

The grouting technology and parameters used in the karst curtain grouting test are determined according to the actual conditions of the construction area and the practice of similar karst curtain grouting projects. The grouting test section is arranged with double rows of linear grouting holes, and the row spacing of the grouting holes is $3 \mathrm{~m}$. First, a row of grouting holes on the side of the mining area is constructed, and then, a row of grouting holes on the side of Qianjiang river is constructed. Each row of grouting holes is constructed in two sequences. The grouting I sequence hole is constructed first, and then, the grouting II sequence hole is constructed. In the grouting test, the top of the curtain is the position, which is $2 \mathrm{~m}$ above the boundary between the rock 


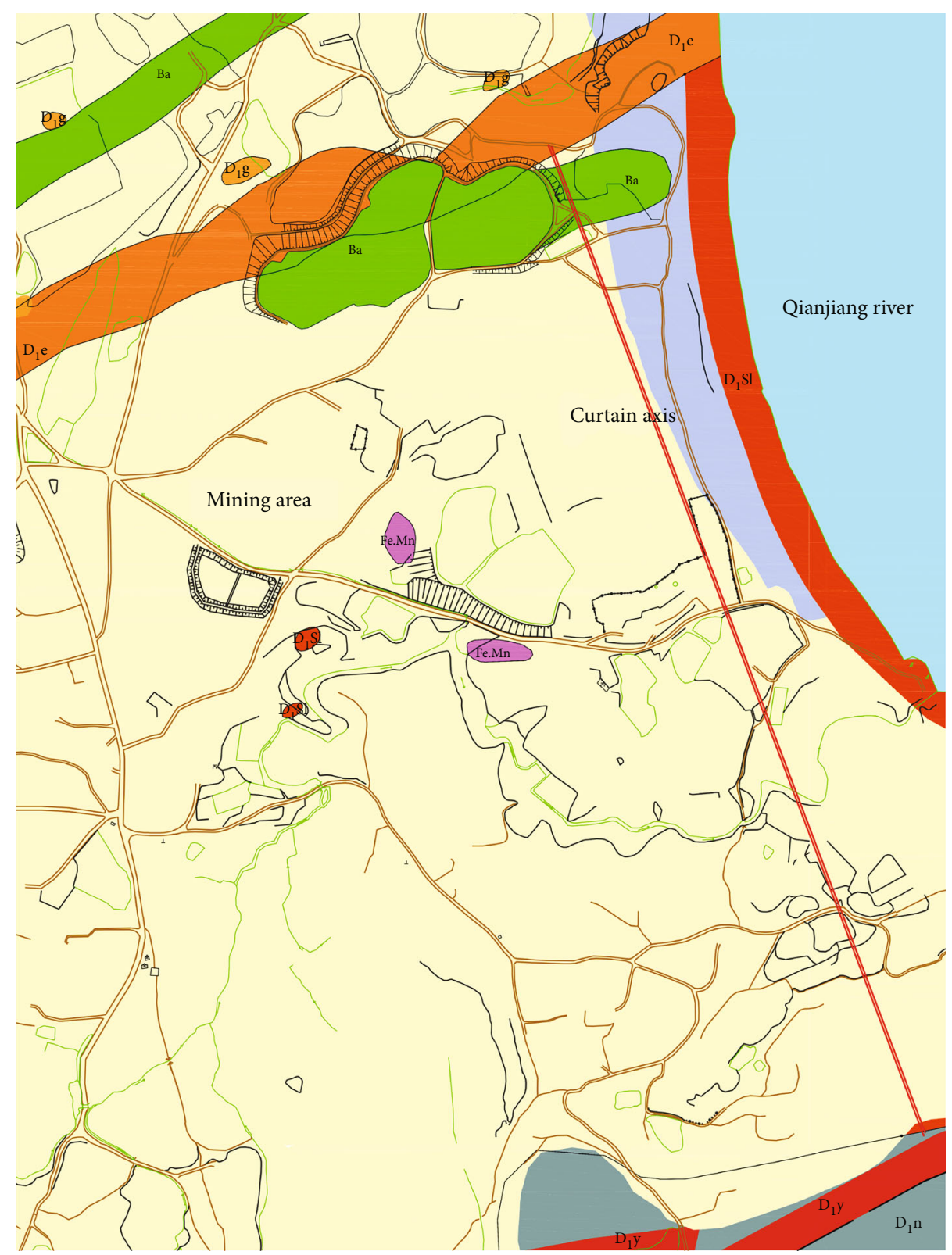

FIgURE 3: The plane position of the axis of the antiseepage curtain.

and soil, and the bottom of the curtain is at the elevation of $-150 \mathrm{~m}$. The initial diameter of the grouting hole is not less than $110 \mathrm{~mm}$, and the end diameter of the grouting hole is not less than $75 \mathrm{~mm}$. The grouting method is the downward-sectional pure-pressure grouting method. The grouting material is the ordinary cement slurry. First, the slurry with lower concentration is used, and then, the concentration of the slurry increases step by step with the process of grouting, and finally, the grouting is finished by the slurry with higher concentration. The inspection standard of karst curtain grouting quality is that when the water permeability of a single inspection hole obtained by the water-pressure test is not more than $5 \mathrm{Lu}$, it is considered that the grouting quality is better and meets the quality acceptance standard.

In the study, 56 groups of grouting data are selected from the field grouting test of the karst curtain grouting project, and an intelligent prediction model of the KCGV is established. There are 28 groups of grouting data in the northern grouting test section (a section with strong karst development) and 28 groups of grouting data in the southern grouting test section (a section with weak karst development). The grouting time $(T)$, the length of grouting section $(L)$, the grouting pressure $(P)$, the grouting flow rate $(Q)$, and the water: cement ratio of slurry $(W: C)$ are taken as the input parameters of the sample, and the KCGV is taken as the output parameter of the sample. 44 groups of grouting data are randomly selected as the learning samples of the prediction model, and the remaining 12 groups of grouting data are used to test the established model. The regression analysis adopts the SVM algorithm in the machine learning library of the Python programming language, which realizes the establishment of the SVM prediction model by giving the 


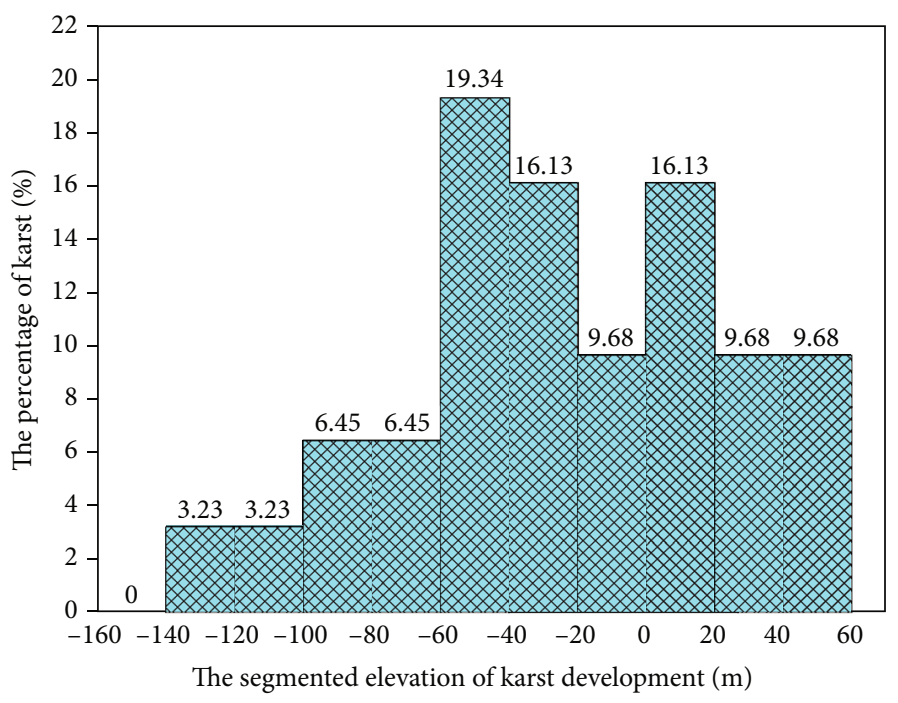

Figure 4: The statistical results of karst revealed by drilling.

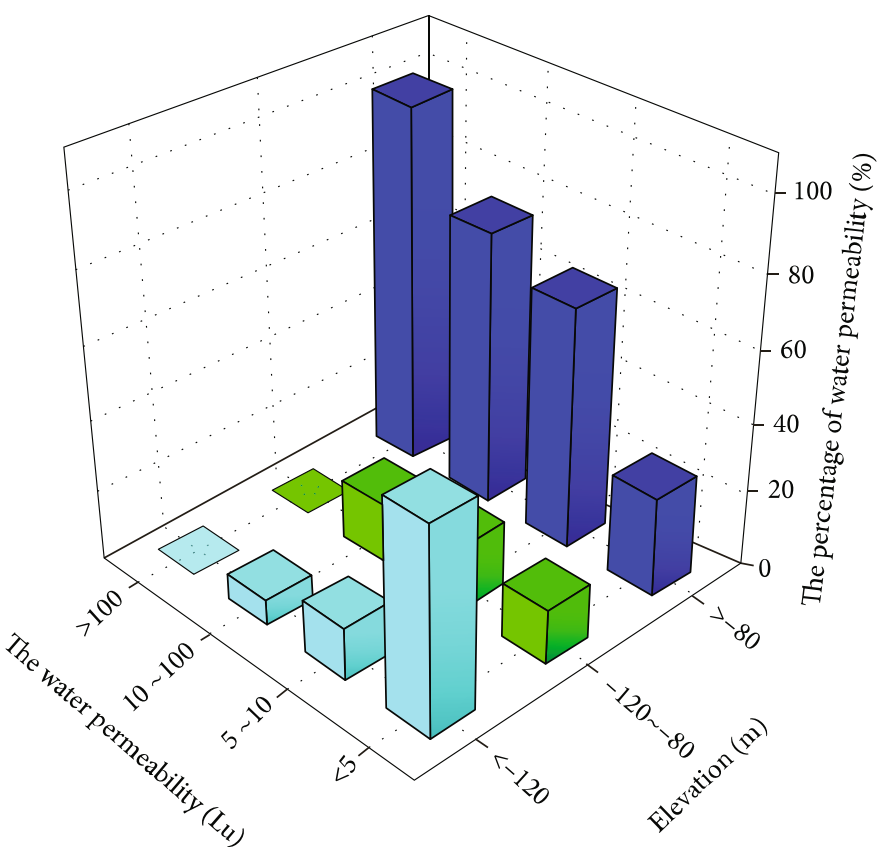

FiguRE 5: The statistical results of the subsection and subelevation of the water-pressure test.

kernel function and penalty parameter, inputting the training samples and completing the regression calculation automatically. In the study, the data set for training and testing is shown in Table 1. The numerical statistics of input and output parameters are shown in Table 2. The box diagrams of the influencing factors are shown in Figure 8.

As can be seen from Table 2 and Figure 8 , the data of $L$, $W: C_{\mathrm{i}}, W: C_{\mathrm{e}}$, and $P$ are relatively fixed and regular, whereas the data of $T, Q_{i}$, and $Q_{e}$ are scattered.

As mentioned above, 56 groups of grouting data are randomly divided into two parts: 44 groups of grouting data of which are the training samples and 12 groups of grouting data of which are the verification samples. The training samples are used to construct the prediction model, whereas the test samples are used to evaluate the performance of the model. In the study, after testing all kinds of kernel functions, the radial basis function is selected as the kernel function, so the hyperparameters of the SVM model are the kernel function parameter $\sigma$ and the penalty parameter $C$. The smaller the kernel function parameter $\sigma$ is, the smaller the regression risk is, and the smoother the regression function curve is, but the greater the structural risk is. The larger the penalty parameter $C$ is, the greater the penalty for the misclassification of the approximation function $S(X)$ of SVM is, and the training accuracy is controlled by $C$. The Grid-Search method in the Python programming language is used to obtain the best hyperparameters. The Grid-Search method is a parameter adjustment method for exhaustive search. 


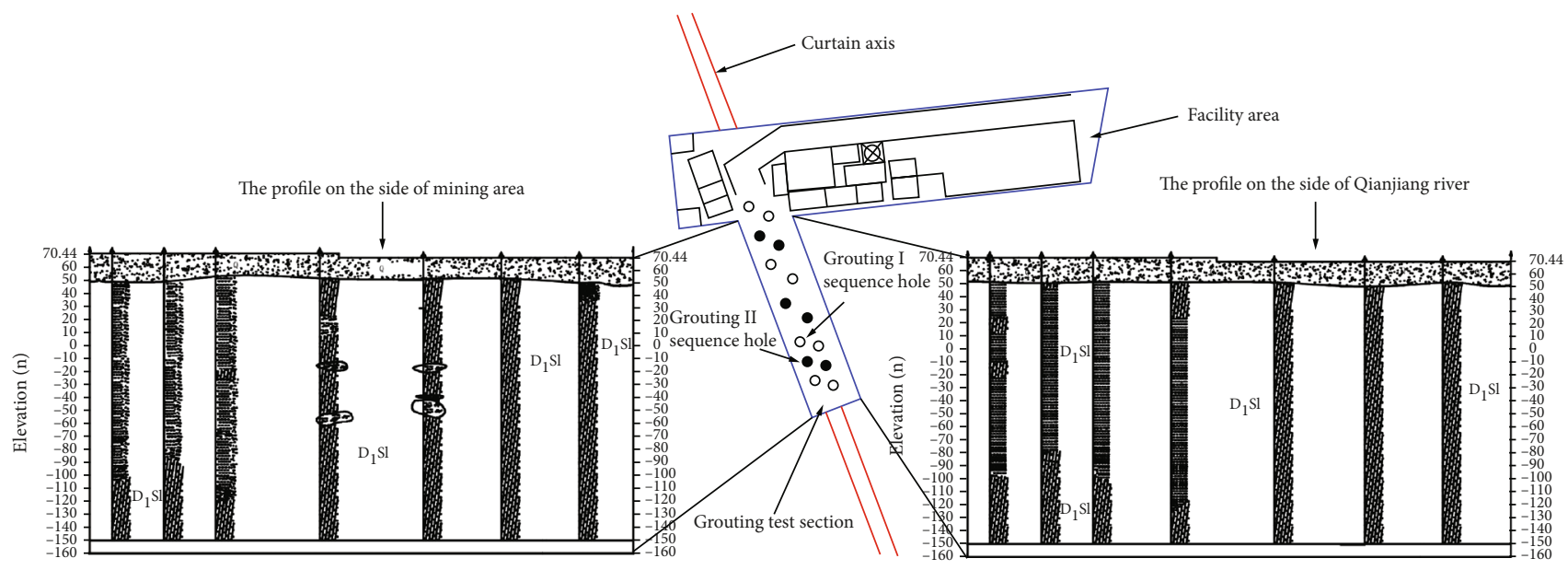

FIGURE 6: The plane layout and profile of the northern grouting test section.

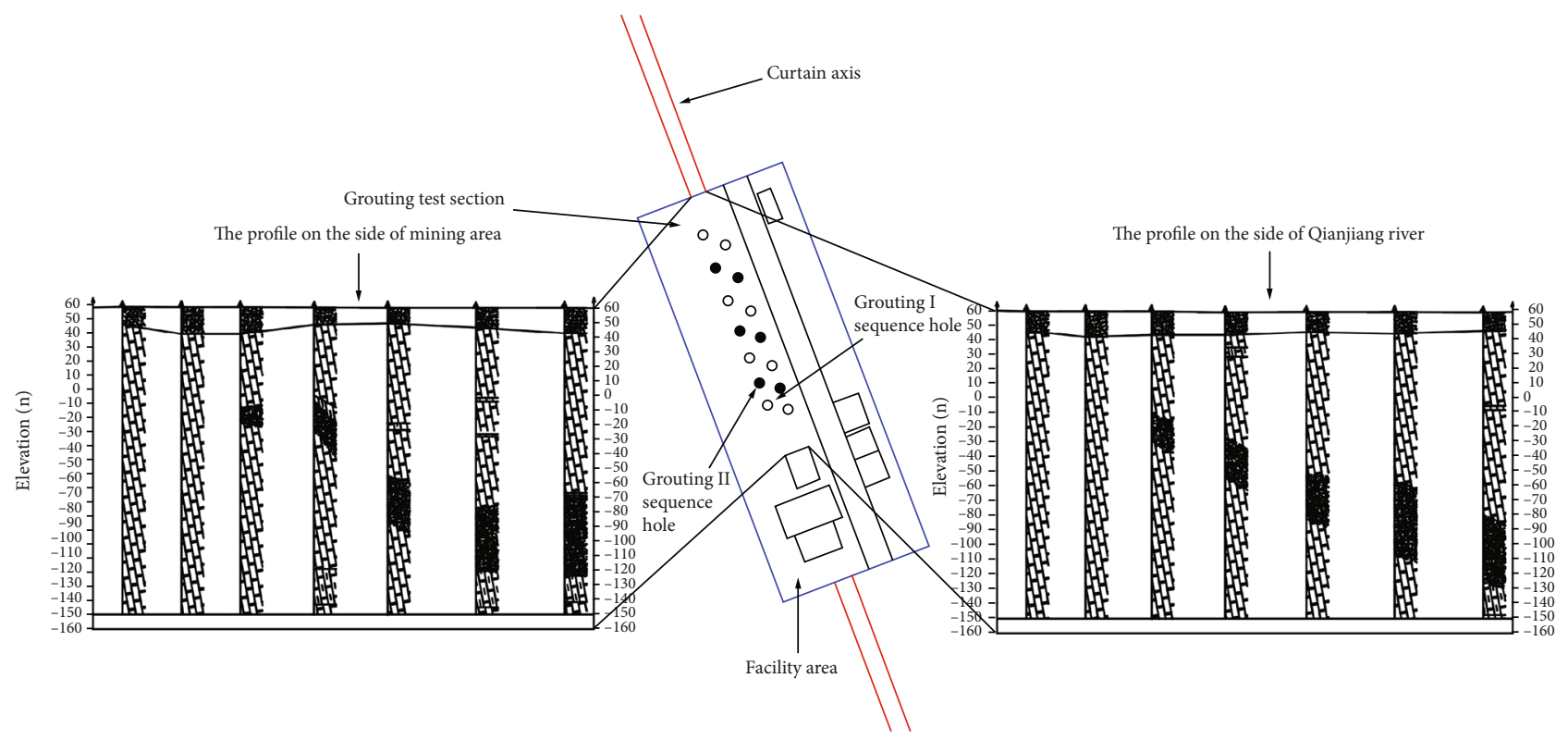

FIGURE 7: The plane layout and profile of the southern grouting test section.

After the range and step of $\sigma$ and $C$ are given, the GridSearch method traverses the regression score in each case by the double-loop traversal means. When the optimal score is selected, the best hyperparameters $C$ is 40 and $\sigma$ is 1.118 . The established intelligent prediction model is used to predict the KCGV. By comparing and analyzing the predicted value and the actual value of the KCGV (Figure 9), it can be seen that the predicted value is very consistent with the actual value. According to the prediction performance indicators of the KCGV (Figure 10), the mean absolute error of the prediction results is $3.47 \mathrm{~L} / \mathrm{m}$, and the mean absolute percentage error of the prediction results is $5.97 \%$; as a result, the prediction accuracy meets the engineering requirements. These show that the established intelligent prediction model of the KCGV based on SVM has excellent prediction effect on the KCGV and can provide practical and beneficial help for the on-site grouting engineering.

\section{Discussion}

In fact, the karst curtain grouting has been one of the most complicated processes in the civil engineering field. Many factors will affect the determination of the KCGV. These influencing factors have the characteristics of randomness and uncertainty, and many of them often influence each other, which leads to a complex nonlinear relationship between the KCGV and its influencing factors. It is difficult to generalize this relationship by using an explicit mathematical regression expression. Therefore, the establishment of a scientific multiparameter comprehensive intelligent prediction model of the KCGV is of great significance to the intelligent development of grouting technology.

At present, the commonly used intelligent prediction methods of the KCGV include the fuzzy theory prediction method, the grey theory prediction method, and the neural 
TABle 1: The data set for training and testing.

\begin{tabular}{|c|c|c|c|c|c|c|c|c|c|c|}
\hline \multirow{2}{*}{$\begin{array}{l}\text { Group } \\
\text { number }\end{array}$} & \multirow[b]{2}{*}{$\begin{array}{c}T \\
(\min )\end{array}$} & \multirow[b]{2}{*}{$\begin{array}{c}L \\
(\mathrm{~m})\end{array}$} & \multicolumn{2}{|c|}{$W: C$} & \multirow[b]{2}{*}{$\begin{array}{c}P \\
(\mathrm{MPa})\end{array}$} & \multicolumn{2}{|c|}{$Q$} & \multicolumn{2}{|c|}{ The KCGV } & \multirow[b]{2}{*}{ Notes } \\
\hline & & & $W: C_{\mathrm{i}}$ & $W: C_{\mathrm{e}}$ & & $\begin{array}{c}Q_{\mathrm{i}} \\
(\mathrm{L} / \mathrm{min})\end{array}$ & $\begin{array}{c}Q_{\mathrm{e}} \\
(\mathrm{L} / \mathrm{min})\end{array}$ & $\begin{array}{l}\text { Actual value } \\
(\mathrm{L} / \mathrm{m})\end{array}$ & $\begin{array}{l}\text { Predicted value } \\
\qquad(\mathrm{L} / \mathrm{m})\end{array}$ & \\
\hline 1 & 81 & 30 & 3 & 1 & 3.5 & 103.5 & 16.5 & 150.96 & - & \\
\hline 2 & 81 & 20 & 3 & 1 & 0.8 & 124.5 & 5.1 & 238.79 & - & \\
\hline 3 & 65 & 30 & 5 & 2 & 5 & 91.6 & 13.7 & 110.63 & - & \\
\hline 4 & 41 & 30 & 5 & 5 & 3.5 & 31.5 & 10.3 & 31.76 & - & \\
\hline 5 & 71 & 30 & 5 & 2 & 3.5 & 122.1 & 13.4 & 124.07 & - & \\
\hline 6 & 50 & 30 & 5 & 5 & 5 & 48.6 & 13.6 & 43.74 & - & \\
\hline 7 & 85 & 30 & 5 & 2 & 3 & 95.2 & 11.5 & 152.9 & - & \\
\hline 8 & 14 & 23.2 & 0.5 & 0.5 & 3.2 & 22.6 & 20.5 & 13.12 & - & \\
\hline 9 & 41 & 30 & 5 & 3 & 2.5 & 31.5 & 20.7 & 35.58 & - & \\
\hline 10 & 56 & 30 & 5 & 5 & 3.5 & 45.1 & 20.4 & 57.32 & - & \\
\hline 11 & 41 & 30.61 & 5 & 3 & 5 & 31.1 & 17.4 & 34.18 & - & \\
\hline 12 & 55 & 30 & 5 & 5 & 4 & 64.5 & 16.2 & 65.46 & - & \\
\hline 13 & 85 & 20 & 5 & 1 & 0.8 & 98.8 & 10.9 & 205.94 & - & \\
\hline 14 & 41 & 31.7 & 5 & 5 & 1.5 & 32.1 & 19.5 & 34.12 & - & \\
\hline 15 & 41 & 30 & 5 & 5 & 4.5 & 42.3 & 14.8 & 34.9 & - & \\
\hline 16 & 66 & 30 & 5 & 2 & 2.5 & 99.1 & 15.4 & 105.89 & - & \\
\hline 17 & 13 & 25.3 & 0.5 & 0.5 & 3.2 & 18 & 16.7 & 8.68 & - & \\
\hline 18 & 65 & 30.5 & 5 & 2 & 5 & 89.8 & 12.5 & 107.25 & - & \\
\hline 19 & 50 & 35.5 & 5 & 3 & 1.5 & 57.8 & 12.8 & 42.5 & - & \\
\hline 20 & 65 & 30 & 5 & 2 & 5 & 96.1 & 14.4 & 101.47 & - & \\
\hline 21 & 12 & 27.7 & 0.5 & 0.5 & 3.2 & 21.3 & 22.1 & 9.39 & - & \\
\hline 22 & 45 & 30.4 & 5 & 5 & 5 & 54.5 & 14.2 & 43.07 & - & The training \\
\hline 23 & 65 & 30 & 5 & 2 & 5 & 108.2 & 16.5 & 115.23 & - & samples \\
\hline 24 & 45 & 30 & 5 & 3 & 2.5 & 55.2 & 10.5 & 41.16 & - & \\
\hline 25 & 51 & 30.88 & 5 & 2 & 5 & 59.1 & 10.1 & 45.91 & - & \\
\hline 26 & 66 & 30.37 & 5 & 2 & 5 & 110.1 & 13.4 & 107.62 & - & \\
\hline 27 & 66 & 30 & 5 & 2 & 1.5 & 100.5 & 16.6 & 108.22 & - & \\
\hline 28 & 65 & 30.5 & 5 & 2 & 5 & 89.8 & 12.8 & 106.76 & - & \\
\hline 29 & 81 & 30 & 5 & 2 & 2.5 & 104.6 & 10.1 & 144.52 & - & \\
\hline 30 & 66 & 30 & 5 & 2 & 3.5 & 109.1 & 13.7 & 109.29 & - & \\
\hline 31 & 12 & 21.5 & 0.5 & 0.5 & 3.2 & 18.1 & 14.4 & 8.94 & - & \\
\hline 32 & 66 & 19 & 5 & 2 & 0.8 & 80.5 & 13.8 & 147.99 & - & \\
\hline 33 & 82 & 30 & 5 & 2 & 2.5 & 82.1 & 12.4 & 124.9 & - & \\
\hline 34 & 80 & 30 & 5 & 2 & 1.5 & 75.6 & 10 & 112.31 & - & \\
\hline 35 & 47 & 30 & 5 & 3 & 2.5 & 33.6 & 15.4 & 38.29 & - & \\
\hline 36 & 85 & 19.5 & 5 & 1 & 0.8 & 56.2 & 8.6 & 129.77 & - & \\
\hline 37 & 67 & 30 & 5 & 2 & 1.5 & 61.4 & 2.5 & 62.06 & - & \\
\hline 38 & 46 & 30 & 5 & 3 & 3 & 58.4 & 10.9 & 43.06 & - & \\
\hline 39 & 56 & 30 & 5 & 5 & 2.5 & 43.1 & 17.4 & 55.44 & - & \\
\hline 40 & 46 & 30 & 5 & 5 & 2 & 53.4 & 6.5 & 38.49 & - & \\
\hline 41 & 76 & 30 & 5 & 2 & 3.5 & 112.4 & 13.2 & 142.88 & - & \\
\hline 42 & 61 & 33.8 & 5 & 2 & 1.5 & 56.3 & 14.3 & 60.89 & - & \\
\hline 43 & 50 & 30 & 5 & 3 & 3 & 43.4 & 14.5 & 49.79 & - & \\
\hline 44 & 55 & 30 & 5 & 2 & 1.5 & 112.4 & 15 & 99.08 & - & \\
\hline 45 & 65 & 30 & 5 & 2 & 3.5 & 98.2 & 15.8 & 107.53 & 108.96 & \\
\hline 46 & 47 & 30 & 5 & 5 & 3.5 & 58.9 & 13.1 & 43.37 & 44.06 & The test samples \\
\hline 47 & 65 & 30.5 & 5 & 2 & 5 & 110.2 & 16.8 & 112.51 & 110.66 & \\
\hline
\end{tabular}


TABLe 1: Continued.

\begin{tabular}{|c|c|c|c|c|c|c|c|c|c|c|}
\hline \multirow{2}{*}{$\begin{array}{l}\text { Group } \\
\text { number }\end{array}$} & \multirow{2}{*}{$\begin{array}{c}T \\
(\min )\end{array}$} & \multirow[b]{2}{*}{$\begin{array}{c}L \\
(\mathrm{~m})\end{array}$} & \multicolumn{2}{|c|}{$W: C$} & \multirow[b]{2}{*}{$\begin{array}{c}P \\
(\mathrm{MPa})\end{array}$} & \multicolumn{2}{|c|}{ Q } & \multicolumn{2}{|c|}{ The KCGV } & \multirow[b]{2}{*}{ Notes } \\
\hline & & & $W: C_{\mathrm{i}}$ & $W: C_{\mathrm{e}}$ & & $\begin{array}{c}Q_{\mathrm{i}} \\
(\mathrm{L} / \mathrm{min})\end{array}$ & $\begin{array}{c}Q_{\mathrm{e}} \\
(\mathrm{L} / \mathrm{min})\end{array}$ & $\begin{array}{l}\text { Actual value } \\
(\mathrm{L} / \mathrm{m})\end{array}$ & $\begin{array}{l}\text { Predicted value } \\
\qquad(\mathrm{L} / \mathrm{m})\end{array}$ & \\
\hline 48 & 58 & 30.96 & 5 & 3 & 5 & 53.1 & 13.1 & 55.7 & 58.06 & \\
\hline 49 & 41 & 30 & 5 & 3 & 3.5 & 33.1 & 19.3 & 34.85 & 38.01 & \\
\hline 50 & 65 & 30 & 5 & 2 & 3.5 & 92.6 & 12.3 & 109.97 & 112.34 & \\
\hline 51 & 50 & 30 & 5 & 3 & 3 & 55.4 & 11.8 & 52.71 & 47.91 & \\
\hline 52 & 72 & 30 & 3 & 1 & 2.5 & 99.8 & 18.1 & 128.62 & 124.31 & \\
\hline 53 & 50 & 30.3 & 5 & 5 & 1.5 & 67.5 & 11.6 & 54.32 & 58.15 & \\
\hline 54 & 65 & 30 & 5 & 2 & 5 & 90.6 & 13.3 & 109.96 & 105.73 & \\
\hline 55 & 65 & 30 & 5 & 2 & 3.5 & 90.8 & 12.5 & 110.09 & 111.29 & \\
\hline 56 & 48 & 30 & 5 & 5 & 5 & 55.6 & 10.6 & 42.21 & 53.66 & \\
\hline
\end{tabular}

TABLE 2: The numerical statistics of input and output parameters.

\begin{tabular}{|c|c|c|c|c|c|c|}
\hline Parameter & Unit & Minimum & Mean & Maximum & Standard deviation & Notes \\
\hline$T$ & $\min$ & 12 & 56.95 & 85 & 17.91 & \\
\hline$L$ & $\mathrm{~m}$ & 19 & 29.15 & 35.5 & 3.27 & \\
\hline$W: C_{\mathrm{i}}$ & - & 0.5 & 4.57 & 5 & 1.23 & \\
\hline$W: C_{\mathrm{e}}$ & - & 0.5 & 2.63 & 5 & 1.42 & Input \\
\hline$P$ & $\mathrm{MPa}$ & 0.8 & 3.20 & 5 & 1.35 & \\
\hline$Q_{i}$ & $\mathrm{~L} / \mathrm{min}$ & 18 & 70.55 & 124.5 & 30.35 & \\
\hline$Q_{e}$ & $\mathrm{~L} / \mathrm{min}$ & 2.5 & 13.81 & 22.1 & 3.75 & \\
\hline The KCGV & $\mathrm{L} / \mathrm{m}$ & 8.68 & 82.25 & 238.79 & 49.95 & Output \\
\hline
\end{tabular}

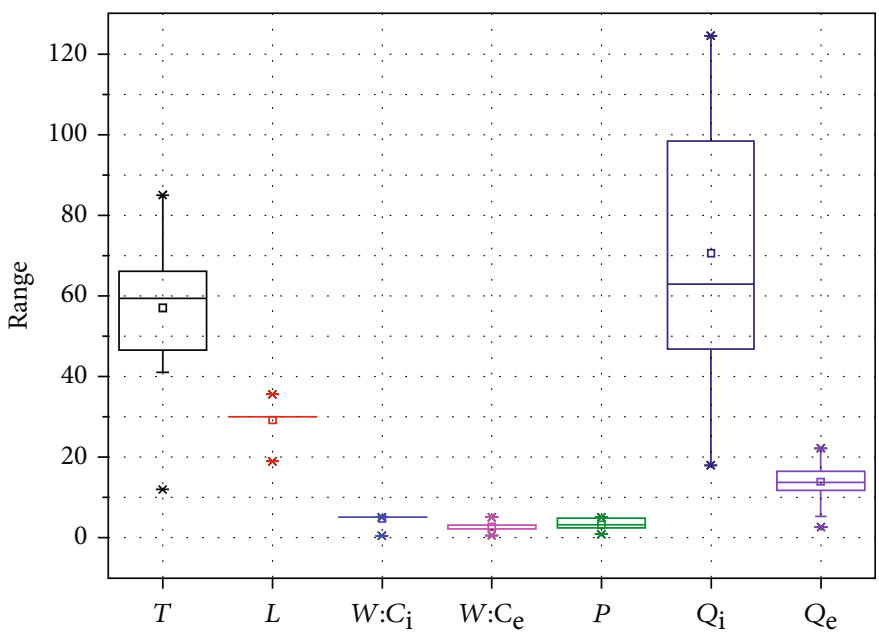

FIgURE 8: The box diagrams of the influencing factors.

network prediction method. Because the degree of membership and the weight of the index of the fuzzy theory prediction method are not easy to be determined, and the evaluation results obtained by different evaluation models are significantly different, the fuzzy theory prediction method is not very practical in engineering practice. The grey theory prediction method is mainly based on a large number of grouting data and does not consider the grouting mecha- nism, so its science and feasibility need to be verified. The neural network prediction method is a learning method based on large samples. Only with enough learning samples can it train a prediction model with high accuracy, but it is impossible to have enough learning samples in engineering practice, and in most cases, it is faced with small sample data. Moreover, the learning speed and efficiency of the method are slow, and the obtained result is usually the local optimal 


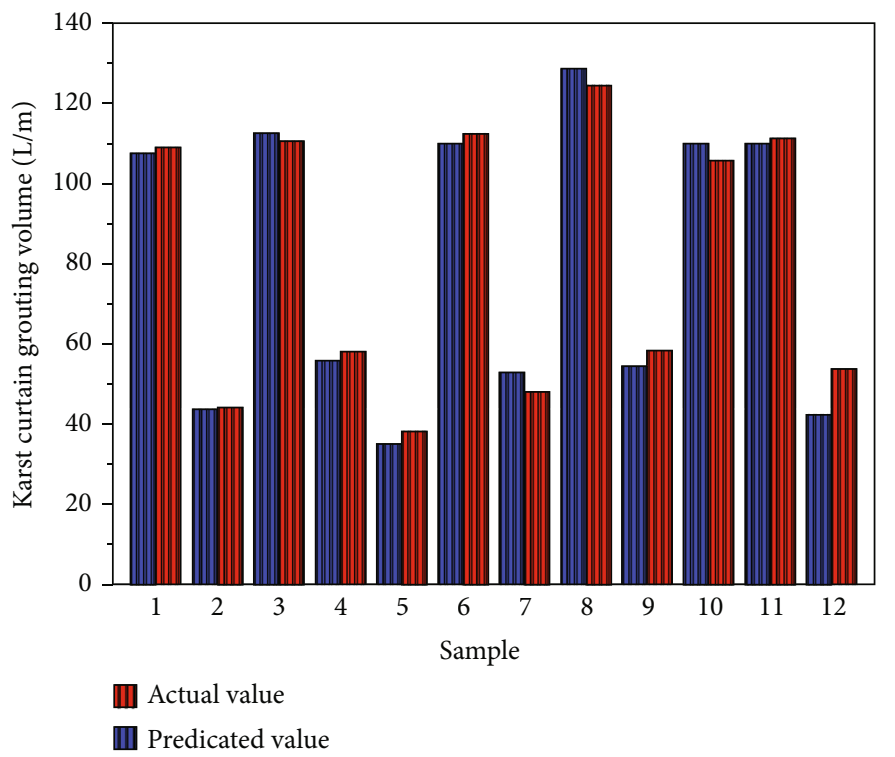

FIGURE 9: The comparison between the actual value and the predicted value of the KCGV.

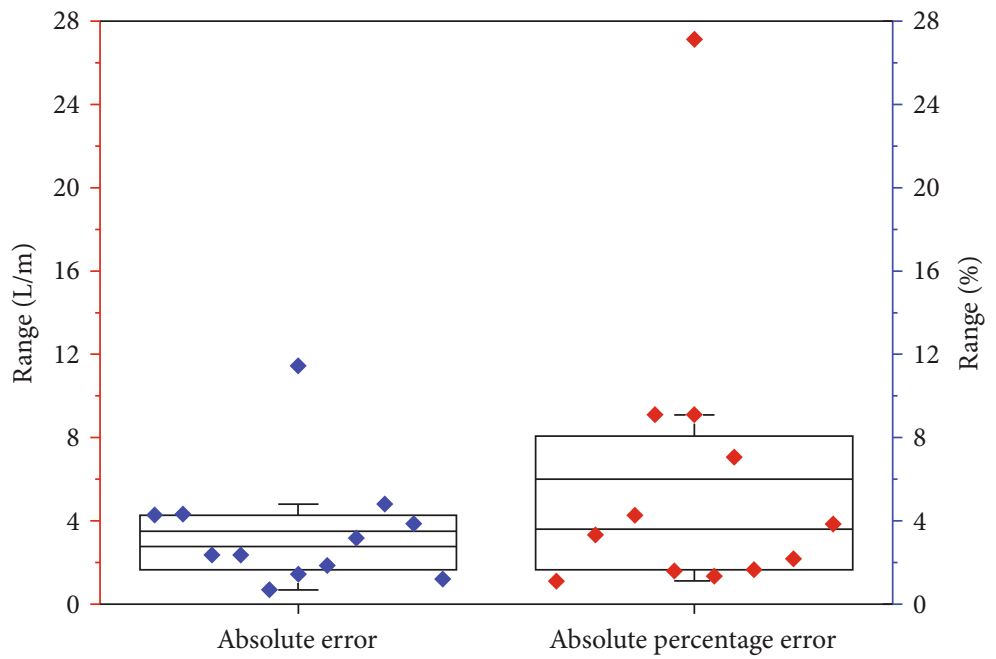

FIGURE 10: The prediction performance indicators of the KCGV.

solution rather than the global optimal solution. Therefore, the reliability and generalization performance of the neural network prediction method are poor. All in all, the application effect of the existing main intelligent prediction methods of the KCGV is not ideal, which leads to the lack of good application promotion.

The intelligent prediction method of the KCGV proposed in this study combines the basic idea of SVM, which solves the problems of few sample data, high dimensions, and nonlinearity encountered in the actual karst curtain grouting engineering, and greatly improves the performance of the prediction model. In the process of establishing the model, the hyperparameters $(C, \sigma)$ of SVM have a great influence on the prediction results, and their reasonable determination directly affects the accuracy and generalization ability of the model. Because the manual search method used to find the parameters of SVM has great blindness, it cannot guarantee that the found hyperparameters are the optimal hyperparameters. In the study, the Grid-Search method in the Python programming language is used to obtain the optimal hyperparameters $(C, \sigma)$. The Grid-Search method is a parameter adjustment method for exhaustive search. After the range and step of the kernel function parameter $\sigma$ and the penalty parameter $C$ are given, the Grid-Search method traverses the regression score in each case by the double-loop traversal means. When the best score is selected, the optimal hyperparameters $(C, \sigma)$ will be obtained. It ensures the prediction accuracy of the model.

In addition, the input factors selected in the study reflect the two control conditions of the slurry diffusion, namely, the grouting construction conditions and the slurry conditions. These parameters are the basic data that can be easily obtained in the process of field grouting and do not need too much exploration test and calculation. Moreover, the 
data source is reliable, the cost is low, and it has strong engineering pertinence and obvious technical feasibility. At the same time, the obtained results are relatively reasonable. Therefore, the proposed prediction method of the KCGV has good applicability and generalization for the karst curtain grouting engineering and can meet the needs of design, construction, and theoretical research of the karst curtain grouting.

In the future research, if the intelligent prediction model of the KCGV based on SVM is embedded into a real-time grouting monitoring system, the real-time guidance can not only avoid the fact that the curtain cannot meet the antiseepage standard of the curtain grouting design due to the lack of grouting volume in the process of grouting construction but also avoid the waste of grouting materials caused by excessive grouting volume. It will help the builders in the grouting site to take control of the grouting quality in a more timely and comprehensive fashion.

\section{Conclusions}

In order to overcome the limitation of the prediction methods of grouting volume commonly used in the karst curtain grouting engineering at present, in this study, the main factors affecting the KCGV are selected as the prediction factors, and the basic ideas of SVM are combined. Based on these, a multiparameter comprehensive intelligent prediction method of the KCGV is proposed. The main conclusions can be drawn as follows:

(1) For the complicated problem of predicting the $\mathrm{KCGV}$, the proposed intelligent prediction method of the KCGV not only makes use of the excellent performance of SVM in solving the problems of small samples, high dimensions, and nonlinearity but also considers the grouting construction conditions and the slurry conditions that control the slurry diffusion, which greatly improves the prediction accuracy and generalization performance of the method

(2) Based on the data of the grouting process and the slurry properties obtained from the field grouting, the proposed method can be used to scientifically predict the KCGV. The procedure is (i) to select the factors that affect the KCGV as input parameters, (ii) to establish an intelligent prediction model based on SVM, and (iii) to predict the KCGV by using the grouting data obtained from the actual grouting project. The method is easy to obtain grouting data from the project site; at the same time, the data source is reliable, the cost is low, and it has strong engineering pertinence and obvious technical feasibility

(3) The proposed intelligent prediction method of the KCGV based on SVM is applied to the typical karst curtain grouting project-the antiseepage curtain grouting project of the Panlong lead-zinc mine, a protective project in the reservoir area of the Datengxia water control project in Guangxi, China. The field grouting data of grouting areas with different charac- teristics of karst development are selected to establish a prediction model. The mean absolute error of the prediction results is $3.47 \mathrm{~L} / \mathrm{m}$, and the mean absolute percentage error of the prediction results is $5.97 \%$. The prediction error is within an acceptable range from an engineering point of view. It shows that the proposed prediction method has certain rationality and applicability in the practical application of the karst curtain grouting engineering

(4) Before the grouting is completed, engineers can easily and accurately check and verify the actual KCGV by using the intelligent prediction model of the KCGV based on SVM and combining it with the main influencing factors of the KCGV. Thus, the method can reduce the number of the field tests, improve economic benefits, and help engineers to strengthen the quality control of the karst curtain grouting projects

\section{Data Availability}

The data used to support the findings of this study are included within the paper.

\section{Conflicts of Interest}

The authors declare that there is no conflict of interest regarding the publication of this paper.

\section{Acknowledgments}

This research was supported by the Fundamental Research Funds for the Central Universities of Central South University (Grant Number: 2020zzts619), the Research and Innovation Project for the Graduate Students of Hunan Province (Grant Number: CX20200349), and the 2020 Innovation and Entrepreneurship Funding Project for the College Students of Central South University (Project Number: S2020105330276, Project Type: Innovation Training Project). The authors would also like to thank the China Hunan Water Resources and Hydropower Survey and Design Research Institute for field test data of the trial grouting boreholes.

\section{References}

[1] F. Guo, G. Jiang, D. Yuan, and J. S. Polk, "Evolution of major environmental geological problems in karst areas of Southwestern China," Environmental Earth Sciences, vol. 69, no. 7, pp. 2427-2435, 2013.

[2] X. Zheng, L. Liu, J. Sun, G. Li, F. Zhou, and J. Xu, "Imaging of underground karst water channels using an improved multichannel transient Rayleigh wave detecting method," PLoS One, vol. 13, no. 6, article e0199030, 2018.

[3] D. J. Ren, S. L. Shen, W. C. Cheng, N. Zhang, and Z. F. Wang, "Geological formation and geo-hazards during subway construction in Guangzhou," Environmental Earth Sciences, vol. 75, no. 11, p. 934, 2016.

[4] Q. L. Cui, S. L. Shen, Y. S. Xu, H. N. Wu, and Z. Y. Yin, "Mitigation of geohazards during deep excavations in karst regions 
with caverns: a case study," Engineering Geology, vol. 195, pp. 16-27, 2015.

[5] I. Yilmaz, "GIS based susceptibility mapping of karst depression in gypsum: a case study from Sivas basin (Turkey)," Engineering Geology, vol. 90, no. 1-2, pp. 89-103, 2007.

[6] S. C. Li, Z. Q. Zhou, L. P. Li, Z. H. Xu, Q. Q. Zhang, and S. S. Shi, "Risk assessment of water inrush in karst tunnels based on attribute synthetic evaluation system," Tunnelling and Underground Space Technology, vol. 38, pp. 50-58, 2013.

[7] Q. L. Cui, H. N. Wu, S. L. Shen, Y. S. Xu, and G. L. Ye, "Chinese karst geology and measures to prevent geohazards during shield tunnelling in karst region with caves," Natural Hazards, vol. 77, no. 1, pp. 129-152, 2015.

[8] C. Zhang, J. Fu, J. Yang, X. Ou, X. Ye, and Y. Zhang, "Formulation and performance of grouting materials for underwater shield tunnel construction in karst ground," Construction and Building Materials, vol. 187, pp. 327-338, 2018.

[9] Y. Zhao, Y. Wang, W. Wang, L. Tang, Q. Liu, and G. Cheng, "Modeling of rheological fracture behavior of rock cracks subjected to hydraulic pressure and far field stresses," Theoretical and Applied Fracture Mechanics, vol. 101, pp. 59-66, 2019.

[10] Y. Zhao, L. Zhang, J. Liao, W. Wang, Q. Liu, and L. Tang, "Experimental study of fracture toughness and subcritical crack growth of three rocks under different environments," International Journal of Geomechanics, vol. 20, no. 8, article 04020128, 2020.

[11] Y. Zhao, Y. Wang, W. Wang, W. Wan, and J. Tang, "Modeling of non-linear rheological behavior of hard rock using triaxial rheological experiment," International Journal of Rock Mechanics and Mining Sciences, vol. 93, pp. 66-75, 2017.

[12] Y. Zhao, L. Zhang, W. Wang, J. Tang, H. Lin, and W. Wan, "Transient pulse test and morphological analysis of single rock fractures," International Journal of Rock Mechanics and Mining Sciences, vol. 91, pp. 139-154, 2017.

[13] Y. Zhao, L. Zhang, W. Wang, W. Wan, and W. Ma, "Separation of elastoviscoplastic strains of rock and a nonlinear creep model," International Journal of Geomechanics, vol. 18, no. 1, article 04017129, 2018.

[14] Y. Wang, H. Zhang, H. Lin, Y. Zhao, and Y. Liu, "Fracture behaviour of central-flawed rock plate under uniaxial compression," Theoretical and Applied Fracture Mechanics, vol. 106, Article ID 102503, 2020.

[15] Y. Wang, H. Lin, Y. Zhao, X. Li, P. Guo, and Y. Liu, "Analysis of fracturing characteristics of unconfined rock plate under edge-on impact loading," European Journal of Environmental and Civil Engineering, vol. 19, pp. 1-16, 2019.

[16] H. Lin, H. Yang, Y. Wang, Y. Zhao, and R. Cao, "Determination of the stress field and crack initiation angle of an open flaw tip under uniaxial compression," Theoretical and Applied Fracture Mechanics, vol. 104, article 102358, 2019.

[17] S. Xie, H. Lin, Y. Wang et al., "A statistical damage constitutive model considering whole joint shear deformation," International Journal of Damage Mechanics, vol. 29, no. 6, pp. 9881008, 2020.

[18] R. H. Cao, P. Cao, X. Fan, X. Xiong, and H. Lin, “An experimental and numerical study on mechanical behavior of ubiquitous-joint brittle rock-like specimens under uniaxial compression," Rock Mechanics and Rock Engineering, vol. 49, no. 11, pp. 4319-4338, 2016.

[19] R. H. Cao, P. Cao, H. Lin, C. Z. Pu, and K. Ou, "Mechanical behavior of brittle rock-like specimens with pre-existing fis- sures under uniaxial loading: experimental studies and particle mechanics approach," Rock Mechanics and Rock Engineering, vol. 49, no. 3, pp. 763-783, 2016.

[20] Y. Zhao, L. Zhang, W. Wang, Q. Liu, L. Tang, and G. Cheng, "Experimental study on shear behavior and a revised shear strength model for infilled rock joints," International Journal of Geomechanics, vol. 20, no. 9, article 04020141, 2020.

[21] X. P. Zhou, "Localization of deformation and stress-strain relation for mesoscopic heterogeneous brittle rock materials under unloading," Theoretical and Applied Fracture Mechanics, vol. 44, no. 1, pp. 27-43, 2005.

[22] X. P. Zhou, Y. X. Zhang, Q. L. Ha, and K. S. Zhu, "Micromechanical modelling of the complete stress-strain relationship for crack weakened rock subjected to compressive loading," Rock Mechanics and Rock Engineering, vol. 41, no. 5, pp. 747-769, 2008.

[23] X. P. Zhou and H. Q. Yang, "Dynamic damage localization in crack-weakened rock mass: strain energy density factor approach," Theoretical and Applied Fracture Mechanics, vol. 97, pp. 289-302, 2018.

[24] Y. Wang, H. Zhang, H. Lin, Y. Zhao, X. Li, and Y. Liu, "Mechanical behavior and failure analysis of fracture-filled gneissic granite," Theoretical and Applied Fracture Mechanics, vol. 108, Article ID 102674, 2020.

[25] H. Lin, X. Zhang, Y. Wang et al., "Improved nonlinear nishihara shear creep model with variable parameters for rocklike materials," Advances in Civil Engineering, vol. 2020, Article ID 7302141, 15 pages, 2020.

[26] C. Wang, Y. Zhao, Y. Zhao, and W. Wan, "Study on the interaction of collinear cracks and wing cracks and cracking behavior of rock under uniaxial compression," Advances in Civil Engineering, vol. 2018, Article ID 5459307, 10 pages, 2018.

[27] X. Shang and H. Tkalčić, "Point-source inversion of small and moderate earthquakes from P-wave polarities and P/S amplitude ratios within a hierarchical bayesian framework: implications for the geysers earthquakes," Journal of Geophysical Research: Solid Earth, vol. 125, no. 2, Article ID e2019JB018492, 2020.

[28] K. Peng, J. Zhou, Q. Zou, and F. Yan, “Deformation characteristics of sandstones during cyclic loading and unloading with varying lower limits of stress under different confining pressures," International Journal of Fatigue, vol. 127, pp. 82-100, 2019.

[29] P. Kang, L. Hong, Y. Fazhi, Z. Quanle, S. Xiao, and L. Zhaopeng, "Effects of temperature on mechanical properties of granite under different fracture modes," Engineering Fracture Mechanics, vol. 226, article 106838, 2020.

[30] K. Peng, Y. Wang, Q. Zou, Z. Liu, and J. Mou, "Effect of crack angles on energy characteristics of sandstones under a complex stress path," Engineering Fracture Mechanics, vol. 218, article 106577, 2019.

[31] W. Yuan, J. X. Li, Z. H. Li, W. Wang, and X. Y. Sun, “A strength reduction method based on the Generalized HoekBrown (GHB) criterion for rock slope stability analysis," Computers and Geotechnics, vol. 117, article 103240, 2020.

[32] J. Niu, B. Wang, C. Feng, and K. Chen, "Experimental research on viscosity characteristics of grouting slurry in a high ground temperature environment," Materials, vol. 13, no. 14, p. 3221, 2020.

[33] Q. S. Zhang, W. Han, S. Li et al., "Comprehensive grouting treatment for water gushing analysis in limestone breccias 
fracture zone," Chinese Journal of Rock Mechanics and Engineering, vol. 31, no. 12, pp. 2412-2419, 2012.

[34] S. Li, R. Liu, Q. S. Zhang, Z. Z. Sun, X. Zhang, and M. T. Zhu, "Research on C-S slurry diffusion mechanism with timedependent behavior of viscosity," Chinese Journal of Rock Mechanics and Engineering, vol. 32, no. 12, pp. 2415-2421, 2013.

[35] R. T. Liu, The study on diffusion and plugging mechanism of quick setting cement based slurry in underground dynamic water grouting and its application, [Ph.D. thesis], Shandong University, Jinan, China, 2012.

[36] Z. Q. Yang, K. P. Hou, T. T. Guo, and Q. Ma, "Study of column-hemispherical penetration grouting mechanism based on Bingham fluid of time-dependent behavior of viscosity," Rock and Soil Mechanics, vol. 32, no. 9, pp. 2697-2703, 2011.

[37] P. T. Milanovic, Water Resources Engineering in Karst, CRC Press, Boca Raton, FL, USA, 2004.

[38] J. D. Niu, B. Wang, G. J. Chen, and K. Chen, "Predicting of the unit grouting quantity in karst curtain grouting by the water permeability of rock strata," Applied Sciences, vol. 9, no. 22, p. $4814,2019$.

[39] A. Sohrabi-Bidar, A. Rastegar-Nia, and A. Zolfaghari, "Estimation of the grout take using empirical relationships (case study: Bakhtiari dam site)," Bulletin of Engineering Geology and the Environment, vol. 75, no. 2, pp. 425-438, 2016.

[40] G. Gustafson and H. Stille, "Prediction of groutability from grout properties and hydrogeological data," Tunnelling and Underground Space Technology, vol. 11, no. 3, pp. 325-332, 1996.

[41] S. M. Sadeghiyeh, M. Hashemi, and R. Ajalloeian, "Comparison of permeability and groutability of Ostur dam site rock mass for grout curtain design," Rock Mechanics and Rock Engineering, vol. 46, no. 2, pp. 341-357, 2013.

[42] F. Song and X. S. Liu, Compilation of Scientific and Technological Achievements of Curtain Grouting Project of Zhongguan Iron Mine, China University of Geosciences Press Co. Ltd., Wuhan, China, 2012.

[43] G. F. Chen and H. B. Tao, "Fuzzy optimization of grouting plan and its engineering application," Express Information of Mining Industry, vol. 11, no. 12, pp. 19-21, 2004.

[44] M. Y. Cheng and N. D. Hoang, "Groutability estimation of grouting processes with microfine cements using an evolutionary instance-based learning approach," Journal of Computing in Civil Engineering, vol. 28, no. 4, article 04014014, 2014.

[45] I. N. Markou, D. N. Christodoulou, and B. K. Papadopoulos, "Penetrability of microfine cement grouts: experimental investigation and fuzzy regression modeling," Canadian Geotechnical Journal, vol. 52, no. 7, pp. 868-882, 2015.

[46] I. N. Markou, D. N. Christodoulou, E. S. Petala, and D. K. Atmatzidis, "Injectability of microfine cement grouts into limestone sands with different gradations: experimental investigation and prediction," Geotechnical and Geological Engineering, vol. 36, no. 2, pp. 959-981, 2018.

[47] F. L. Li and Q. T. Shen, "Predictive model of the grouting pressure based on improved GM $(1,1)$," Techniques of Automation and Applications, vol. 27, no. 3, pp. 12-15, 2008.

[48] S. H. Wang and Z. Hao, "The genetic algorithm-neural network method to forecast the miniature crack grouting in rock matrix," Chinese Journal of Geotechnical Engineering, vol. 23, no. 5, pp. 572-575, 2001.
[49] Z. Hao, B. Liu, X. R. He, and Z. Q. Zhang, "Application of artificial neural network in grouting engineering of rock mass," Non-Ferrous Mining and Metallurgy, vol. 14, no. 5, pp. 3-5, 1998.

[50] E. Tekin and S. O. Akbas, "Artificial neural networks approach for estimating the groutability of granular soils with cementbased grouts," Bulletin of Engineering Geology and the Environment, vol. 70, no. 1, pp. 153-161, 2011.

[51] E. Tekin and S. O. Akbas, "Predicting groutability of granular soils using adaptive neuro-fuzzy inference system," Neural Computing and Applications, vol. 31, no. 4, pp. 1091-1101, 2019.

[52] K. W. Liao, J. C. Fan, and C. L. Huang, "An artificial neural network for groutability prediction of permeation grouting with microfine cement grouts," Computers and Geotechnics, vol. 38, no. 8, pp. 978-986, 2011.

[53] L. Jedlinski and J. Jonak, "Early fault detection in gearboxes based on support vector machines and multilayer perceptron with a continuous wavelet transform," Applied Soft Computing, vol. 30, pp. 636-641, 2015.

[54] N. Verbiest, J. Derrac, C. Cornelis, S. Garcia, and F. Herrera, "Evolutionary wrapper approaches for training set selection as preprocessing mechanism for support vector machines: experimental evaluation and support vector analysis," Applied Soft Computing, vol. 38, pp. 10-22, 2016.

[55] H. Dai, H. Zhang, W. Wang, and G. Xue, "Structural reliability assessment by local approximation of limit state functions using adaptive Markov chain simulation and support vector regression," Computer-Aided Civil and Infrastructure Engineering, vol. 27, no. 9, pp. 676-686, 2012.

[56] S. Wang, S. Qiu, W. Wang, D. Xiao, and K. C. P. Wang, "Cracking classification using minimum rectangular coverbased support vector machine," Journal of Computing in Civil Engineering, vol. 31, no. 5, article 04017027, 2017.

[57] Y. Zhou, W. Su, L. Ding, H. Luo, and P. E. D. Love, "Predicting safety risks in deep foundation pits in subway infrastructure projects: support vector machine approach," Journal of Computing in Civil Engineering, vol. 31, no. 5, article 04017052, 2017.

[58] N. D. Hoang and D. T. Bui, "Predicting earthquake-induced soil liquefaction based on a hybridization of kernel Fisher discriminant analysis and a least squares support vector machine: a multi-dataset study," Bulletin of Engineering Geology and the Environment, vol. 77, no. 1, pp. 191-204, 2018.

[59] J. S. Chou and A. D. Pham, "Smart artificial firefly colony algorithm-based support vector regression for enhanced forecasting in civil engineering," Computer-Aided Civil and Infrastructure Engineering, vol. 30, no. 9, pp. 715-732, 2015.

[60] G. Mountrakis, J. Im, and C. Ogole, "Support vector machines in remote sensing: a review," ISPRS Journal of Photogrammetry and Remote Sensing, vol. 66, no. 3, pp. 247-259, 2011.

[61] C. W. Hsu and C. J. Lin, "A simple decomposition method for support vector machines," Machine Learning, vol. 46, pp. 291314, 2002.

[62] S. S. Keerthi and C. J. Lin, "Asymptotic behaviors of support vector machines with Gaussian kernel," Neural Computation, vol. 15, no. 7, pp. 1667-1689, 2003. 